\title{
DIREITO À SAÚDE E JUDICIALIZAÇÃO: UM ESTUDO SOBRE A EFICÁCIA DO FÓRUM NACIONAL DO JUDICIÁRIO PARA A SAÚDE
}

\author{
RIGHT TO HEALTH AND JUDICIALIZATION: A STUDY ABOUT ITS \\ EFFICIENCY OF THE NATIONAL JUDICIARY FORUM ON HEALTH
}

\author{
Edith Maria Barbosa Ramos ${ }^{1}$ \\ Isadora Moraes Diniz ${ }^{2}$
}

\section{RESUMO}

Nos últimos anos, a judicialização da saúde se tornou uma questão problemática para o Judiciário. Nesse contexto, o Conselho Nacional de Justiça apresenta-se como um ator de uma política pública judiciária de defesa e garantia do direito à saúde, através da instituição do Fórum Nacional do Judiciário para a Saúde. A pesquisa objetiva avaliar a eficácia da atuação do Fórum da Saúde no oferecimento de soluções e alternativas para o processo da judicialização da saúde. A pesquisa foi realizada no ano de 2015. Desenvolveu-se pesquisa descritiva e exploratória, com procedimento bibliográfico, documental e entrevista semiestruturada.

Palavras-chave: Judicialização da saúde. Fórum da Saúde. Eficácia.

\begin{abstract}
In the past few years, the judicialization of health has become a problematic theme to the Judiciary. In this contexto, the National Justice Council to puts itself in the role of promoting a judicial public policy for defense and guarantee of health rights, by the National Judiciary Forum on Health institution. This study aims to evaluate the efficacy of the National Forum practice in offering solutions and alternatives to the health judicialization process. The research was carried out during 2015. Developed descriptive and exploratory research, with bibliographic procedure, documentary and semi-structured interview.
\end{abstract}

Keywords: Judicialization of health. Forum on Health. Efficacy.

\footnotetext{
${ }^{1}$ Doutora em Políticas Públicas pela Universidade Federal do Maranhão, - UFMA, Maranhão, (Brasil). Mestre em Direito pela Universidade Federal de Minas gerais - UFMG, Minas Gerais (Brasil). Professora Adjunta da Pós-Graduação e Graduação.

${ }^{2}$ Mestre em Direito pela Universidade Federal do Maranhão - UFMA, Maranhão (Brasil).

E-mail: isadoramdiniz@hotmail.com
} 


\section{INTRODUÇÃO}

A Constituição Federal de 1988 foi o primeiro texto constitucional brasileiro a tratar a saúde como direito, inserindo-a no rol dos direitos fundamentais sociais, devendo ser realçado que, embora seja um direito social, o direito à saúde possui também uma dimensão subjetiva individual, sendo a um só tempo um direito de caráter programático e um direito individual, oponível ao Estado judicialmente.

É na dimensão individual que o direito à saúde vem despertando nos últimos anos a preocupação da sociedade brasileira, pois, em que pese a série de serviços assegurados em lei à população, a gestão do Sistema Único de Saúde vem encontrando dificuldade na efetivação das prestações em saúde.

Diante da incapacidade de o SUS atender a totalidade das demandas sociais, vem se fortalecendo cada vez mais o processo de judicialização da saúde, que pode ser entendido como um "fenômeno político-social, no sentido do alargamento das possibilidades de ação junto ao Poder Judiciário, e do aumento exponencial do número de demandas, de caráter individual, interpostas junto a esse poder, que versam sobre questões de saúde" (DELDUQUE, MARQUES, CIARLINI, 2013, p. 183).

As decisões judiciais impactam diretamente na alocação de recursos públicos, como se apreendeu de informações constantes no Relatório Sistêmico de Fiscalização da Função Saúde do Tribunal de Contas da União ao apontar que os valores gastos pelo Ministério da Saúde para o cumprimento de decisões judiciais, através de depósito judicial ou de repasses a Estados e Municípios, saltaram de R\$ 116 mil em 2005, para mais de R\$ 68 milhões em 2012. “Já os gastos do Ministério com aquisição direta de medicamentos, equipamentos e insumos concedidos em decisões judiciais passou de $\mathrm{R} \$ 2,4$ milhões em 2005, para R \$ 287,8 milhões em 2012" (BRASIL, 2015).

Nesse contexto, o encontro de alternativas para o processo de judicialização da saúde se tornou uma prioridade para os Poderes Executivo e Judiciário. Com relação ao Judiciário, a maior ação tomada nos últimos anos foi a instituição do Fórum da Saúde pelo Conselho 
Nacional de Justiça, sendo o objetivo do trabalho avaliar a sua eficácia após cinco anos de existência.

Trata-se de uma pesquisa descritiva e exploratória, com utilização de procedimento bibliográfico, documental e entrevista semiestruturada. Para alcançar o objetivo pretendido, foi realizada coleta na legislação vigente e também em documentos, artigos e doutrina relacionados ao tema. Aplicou-se metodologia qualitativa, visto que se pretendeu realizar uma avaliação da eficácia da atuação do Fórum da Saúde no oferecimento de soluções e alternativas para o processo da judicialização da saúde. A pesquisa foi realizada no ano de 2015.

O presente artigo foi construído em dois capítulos, no primeiro busca-se compreender o processo de judicialização da saúde e sua intercessão com a gestão pública. No segundo capítulo analisou-se a forma de estruturação e a eficácia da política judiciária desenvolvida pelo Conselho Nacional de Justiça para o fornecimento de soluções e alternativas para a judicialização da saúde.

Por fim, concluiu-se que o processo de judicialização exerceu influência decisiva na constituição do Fórum Nacional da Saúde, que tem apresentado grande dificuldade na implementação de políticas públicas judiciárias de saúde, fundamentalmente, em virtude da fragmentação e descontinuidade das ações desenvolvidas pelo CNJ.

\section{A JUDICIALIZAÇÃO DA SAÚDE}

Nos últimos anos, a judicialização da saúde se tornou uma questão problemática para o Poder Judiciário, não apenas pela grande quantidade de ações em tramitação, mas, sobretudo, em virtude das especificidades e complexidades que giram em torno do tema, as quais vão desde a legitimidade deste Poder para o controle das políticas públicas até a dificuldade da especificação do âmbito de proteção do direito à saúde, as questões orçamentárias e técnicas, dentre outras.

As decisões sobre prestações em saúde implicam a própria redefinição do papel do Poder Judiciário e dos limites dos demais Poderes, na medida em que interferem na redefinição da alocação de recursos públicos e no controle das ações (comissivas e omissivas) da Administração na esfera dos direitos fundamentais sociais.

Frente ao déficit ou carência de políticas públicas, a judicialização é fator 
imprescindível para a efetivação do direito fundamental à saúde. Todavia, neste campo, o Poder Judiciário tem que agir com cautela, pois tal fenômeno pode abalar a própria estabilidade das instituições democráticas, na medida em que, a partir da judicialização das questões de saúde, o Poder Judiciário é obrigado a se imiscuir nas áreas de alocação de recursos e de prioridades do Estado, sem estar devidamente preparado para tanto.

Faz-se necessária a disseminação da percepção de que a universalidade do direito não significa que toda e qualquer prestação em saúde requerida pelas partes deva ser atendida, devendo o Poder Judiciário estar preparado para diferenciar aquilo que se refere apenas a um interesse privado da parte e aquilo que de fato está inserido no âmbito de proteção à saúde.

No entanto, o que se tem observado em geral, segundo Souza (2013, p. 166), é a disseminação entre os magistrados de uma interpretação judicial do direito à saúde “extremamente pródiga e expansiva, da qual se extraem - sem a necessidade de interposição legislativa - obrigações estatais de fornecer a todos, gratuitamente, o completo bem-estar físico, mental e social”, sem maiores preocupações quanto à definição de um âmbito claro e coerente de proteção ao direito à saúde. Souza (2013, p. 167-168) ainda aponta que

\footnotetext{
[...] na grande maioria dos casos, o que vemos nos autos dos processos em que se discute o tema é a invocação genérica do art. 196 da CF, acompanhado de uma alusão meramente retórica de conceitos como o da reserva do possível, o da dignidade da pessoa humana e o do mínimo existencial. Há uma quantidade impressionante de leis e atos normativos secundários normatizando o complexo sistema de saúde brasileiro e o conhecimento deles facilitaria sobremaneira solucionar questões controvertidas como a discussão sobre a responsabilidade solidária ou subsidiária dos entes federados ou as querelas sobre fornecimento de medicamentos.
}

Com efeito, é preciso haver uma racionalidade na concessão de medidas judiciais em saúde, sendo as diretrizes do SUS estabelecidas na Constituição Federal, na Lei Orgânica da Saúde e demais atos normativos, importantes marcos para a concretização do direito à saúde, para, diante da sua complexidade e multiplicidade de prestações, especificar o âmbito de abrangência do direito, ou pelo menos, aquilo que ele não comporta.

Mas essa racionalização não significa adoção de uma interpretação restritiva no tocante às obrigações estatais em relação ao direito à saúde, que muitas vezes é adotada pela Administração Pública, "pressionada pelas decisões judicias e por uma série de leis que criam direitos sem a previsão das fontes de receitas necessárias para sua efetivação" (SOUZA, 2013, p. 166).

É preciso encontrar um meio termo entre a interpretação ampliada que o Poder Judiciário, em geral, vem dando ao art. 196 da CF e a interpretação restritiva da 
Administração. Se é certo que o direito fundamental à saúde possui um âmbito de proteção extremamente amplo, também deve ser livre de dúvidas que o princípio da reserva do possível não pode servir de obstáculo à efetivação de uma prestação social quando esta estiver relacionada a uma ação já prevista em uma política pública existente, uma vez que, neste caso, os Poderes majoritários, desde o momento da criação da política, já fizeram as avaliações dos custos e possibilidades de implementação da política, não se podendo conceber, diante da universalidade do direito à saúde (RAMOS, 2014), que uma política pública nessa área seja criada para atender uns e outros não, a depender das reservas financeiras do Estado.

O discurso da reserva do possível somente pode servir de argumento de defesa ao Estado no que se refere a tratamentos e medicamentos não previstos em políticas públicas, devendo-se frisar, no entanto, que mesmo nos casos em que se admita a invocação da reserva do possível para justificar a não concessão de uma prestação em saúde, faz-se necessário evitar a utilização do princípio como uma argumentação vazia de defesa, exigindo-se do Estado a comprovação da alegação de insuficiência de recursos públicos.

Além da reserva do possível, há outro obstáculo frequentemente apresentado contra a efetivação judicial de políticas públicas, qual seja: o fato de que a concessão judicial de uma prestação em saúde para determinado indivíduo acaba por desestruturar todo o sistema público, não sendo possível que "o Judiciário sirva de instrumento para impor à Administração, em favor apenas dos demandantes, deveres estatais que pela própria essência seriam aproveitados por toda a sociedade", fragmentando e desestruturando o sistema de saúde (PERLINGEIRO, 2012, p. 195-196).

Tal concepção reflete a ideia de que o direito à saúde é um direito social, que deve ser implementado mediante políticas sociais e econômicas, não gerando um direito subjetivo ao indivíduo e, por isso, não pode ser gozado diretamente por cada indivíduo. Entretanto, apesar de a Constituição Federal inserir o direito à saúde no rol dos direitos sociais (art. $6^{\circ}$ ), prevendo que o Estado deva garanti-lo por meio de políticas sociais e econômicas para a prevenção dos riscos da doença e para a promoção, proteção e recuperação da saúde, é inconteste que o direito à saúde não pode ser compreendido apenas pela ótica coletiva.

Com efeito, "do ponto de vista das pessoas, a saúde é claramente, uma questão que envolve cada um dos indivíduos, não sendo possível raciocinar apenas pelo prisma coletivo" (BRITO FILHO, 2014, p. 172). Brito Filho (2014, p. 172) adverte que: 
Pensar diferente é imaginar que o ser humano, em relação ao direito à saúde, é somente uma parte de um todo, e que basta uma política geral para que o direito seja preservado, como se os problemas de saúde não se manifestassem de maneira individualizada em cada pessoa; como se as particularidades dos indivíduos não os levassem a ter ou não determinados agravos à sua perfeita condição física e mental; como se as necessidades de todos fossem sempre as mesmas. É óbvio que não é assim.

O direito à saúde, portanto, além da perspectiva social, possui uma dimensão individual, podendo o Poder Judiciário agir para proteger o direito subjetivo à saúde de qualquer pessoa que vá a juízo requerer a sua proteção.

Assim, se o Poder Judiciário está diante de uma prestação que deveria ser oferecida pelo Estado, em que pese a inexistência ou insuficiência das políticas públicas, tem de agir para conferir a máxima eficácia ao direito à saúde previsto na Constituição Federal.

No entanto, é importante frisar que tal ideia não implica na defesa de que toda e qualquer pretensão nesta seara deve ser tutelada pelo Poder Judiciário. É preciso saber diferenciar as prestações que estão compreendidas dentro do direito subjetivo individual e, por isso mesmo, exigíveis, e as que se inserem no contexto de um direito social, que tem um viés programático incontestável. É nesse ponto que reside uma das maiores complexidades do direito à saúde, sendo que, de acordo com Werner (2008, p. 94-95):

\begin{abstract}
A análise dos casos concretos demonstra que os operadores do direito, em sua maioria, não foram e não estão suficientemente preparados para caminhar na área do direito social à saúde, carecendo muitas decisões de uma linha de argumentação mediadora da interligação de um direito social à prestação e um direito subjetivo individual, estabelecendo-se uma relação onde direito e deveres se encontram em conexão.

Quanto mais se compreender a estrutura integral do direito à saúde na Constituição Federal e a finalidade imposta pelo constituinte originário, haverá menos espaço para a extensão indevida de seus limites e, conseqüentemente, mais proximidade com o padrão de igualdade e justiça distributiva.
\end{abstract}

Dessa forma, em virtude da abstração e complexidade do direito à saúde, os intérpretes do direito têm dificuldade de traçar os seus limites. Assim, casuísmos se tornaram cada vez mais frequentes, predominando a compreensão de que o direito à saúde possui somente uma dimensão subjetiva, não podendo ser denegado de forma alguma, posicionamento que dificulta a necessária diferenciação entre demandas originadas de uma real omissão do Poder Público na concretização do direito à saúde e aquelas que pleiteiam um benefício que foge da necessidade básica (WERNER, 2008).

A inexistência de parâmetros institucionais para a aferição dos limites e possibilidades do direito à saúde propicia a existência de sentenças judiciais extremamente díspares, uma vez que os juízes, por muitas vezes desconhecerem as questões técnicas e 
científicas imbricadas nas demandas de saúde, prolatam sentenças que não compreendem a real dimensão da garantia, deixando-se levar pelo forte apelo emocional dos casos que apreciam e desconsiderando as opções feitas pelos Poderes Executivo e Legislativo, e também pela sociedade, as quais também são escolhas legítimas.

Nesse contexto, a judicialização da saúde se tornou um fenômeno cujos efeitos transcendem os limites do Poder Judiciário, afetando o orçamento público, a relação deste Poder com o Executivo e com toda a comunidade, tornando-se, assim, uma questão de grande relevância para o Poder Judiciário, que passou a se debruçar sobre o tema a fim de elaborar uma política judiciária institucional a partir da convocação da Audiência Pública no 4.

A Audiência teve por fim esclarecer as questões técnicas, científicas, administrativas, políticas e econômicas envolvidas nas demandas judiciais sobre a saúde, através da oitiva de representantes de todos os Poderes da República, juristas, gestores públicos, profissionais da área da saúde e setores da sociedade civil.

Os participantes da Audiência Pública da Saúde, além de exporem argumentos favoráveis e desfavoráveis à intervenção judicial, também apresentaram uma série de propostas para a correção das disfuncionalidades geradas pelo fenômeno da judicialização da saúde. Dentre elas, destacam-se duas propostas: o fornecimento de assessoria técnica aos juízes e o diálogo permanente entre o Poder Judiciário e o Poder Executivo em relação à saúde, criando-se, por exemplo, câmaras prévias de conciliação.

Quanto à proposta de fornecimento de assessoria técnica aos magistrados, é importante destacar que ela se baseou nos núcleos de apoio técnico ao Poder Judiciário, presentes nos Estados do Rio de Janeiro, São Paulo e Minas Gerais. Nesses Estados, “os NATs têm como missão oferecer assessoria e consultoria técnica aos magistrados para apoiálos em suas decisões", sendo "formados por equipe multidisciplinar encarregada de elaborar pareceres técnicos que explicam tanto aspectos clínicos como de políticas públicas em saúde relacionadas à demanda judicial" (GOMES, et al., 2014, p. 150).

A instituição de um diálogo permanente entre o Poder Judiciário e o Poder Executivo, por sua vez, foi vista, por muitos, como a forma mais viável de mitigar a judicialização. Essas duas propostas específicas influenciaram a edição, pelo Conselho Nacional de Justiça, da Recomendação $n^{\circ} 31$ e da Resolução $n^{\circ} 107$, que visaram o estabelecimento, dentre outras medidas, dos núcleos técnicos e do diálogo entre os Poderes. 


\section{O FÓRUM NACIONAL DO JUDICIÁRIO PARA A SAÚDE}

No tópico anterior, realçou-se a dificuldade dos magistrados em lidar com as ações envolvendo o direito à saúde e os reflexos das decisões judiciais na seara do Poder Executivo, circunstâncias que acabaram por levar o Poder Judiciário a dar relevo à temática da judicialização da saúde.

Ressalte-se, todavia, que não é só porque uma questão adquiriu relevância política que será enfrentada pelo Poder Público, sendo que é na fase da "agenda setting" que se decide se um tema deve ser efetivamente enfrentado ou ser excluído ou adiado para uma data posterior, nada obstante a sua importância.

A entrada de problema na agenda política depende de diversas circunstâncias: a relação custo-benefício, as chances do tema se impor na arena política, o perfil dos responsáveis pela elaboração das políticas e da instituição envolvida, dentre outras.

Sobre a construção da agenda do Conselho Nacional de Justiça, Sadek (2010) observa que as características individuais dos Presidentes do Conselho influenciam a agenda política do órgão. Por essa razão, aponta que a pauta do Conselho Nacional de Justiça tem mudado conforme a sua Presidência:

[...] o primeiro, Nelson Jobim, encarregou-se, sobretudo de criar o órgão; Ellen Gracie, em seguida deu ênfase à informatização; Gilmar Mendes privilegiou a formulação de políticas de gestão e de defesa de direitos e garantias fundamentais (SADEK, 2010, p. 16).

Assim, tem-se que o tema da judicialização da saúde entrou na agenda do CNJ, sobretudo, em razão da influência do então Presidente do Conselho, o Ministro Gilmar Mendes, que, conforme observa Fregale Filho (2013, p 99), “focou na elaboração de políticas de gestão e de defesa de direitos e garantias fundamentais, desenvolvendo um planejamento estratégico para o Poder Judiciário".

Para Gilmar Mendes, o Conselho não tem apenas a missão de concretizar a promessa de um Poder Judiciário célere e efetivo, mas também de defender os direitos fundamentais, "assumindo a sua responsabilidade pela inclusão social e proteção efetiva dos direitos fundamentais e fortalecendo a crença no valor inquestionável da cidadania" (MENDES, 2012).

Seguindo essa linha de política judiciária do Ministro Gilmar Mendes, foram editadas pelos CNJ a Recomendação no 31, de 30 de março de 2010, e a Resolução n 107 , de 
6 de abril de 2010.

O primeiro ato normativo recomenda aos Tribunais a adoção de medidas visando melhor subsidiar os magistrados e demais profissionais da seara jurídica, para o fim de assegurar maior eficiência na solução das demandas judiciais envolvendo a assistência à saúde.

Através da Recomendação $n^{\circ} 31 / 2010$, o Conselho assume que é preciso realizar mudanças na forma como o Poder Judiciário vem garantindo a efetivação do direito à saúde, considerando o grande número de demandas envolvendo a assistência à saúde em tramitação nos Tribunais brasileiros e o representativo dispêndio de recursos públicos decorrente desses processos judiciais.

O CNJ reconhece, também, a necessidade de que os gestores sejam ouvidos antes da concessão de provimentos judiciais de urgência, a fim de prestigiar sua capacidade gerencial, as políticas públicas existentes e a organização, sustentabilidade e gerenciamento do sistema público de saúde.

A edição da Recomendação $n^{\circ} 31$ foi motivada, ainda, pelas constatações feitas na Audiência Pública $n^{\circ} 4$ com relação às demandas judiciais que objetivam o fornecimento de prestações de saúde. Verificou-se, de um modo geral, que os magistrados têm dificuldades em lidar com tais demandas, uma vez que estas exigem conhecimentos técnicos específicos e muitas vezes são deficitárias as informações clínicas prestadas pelas partes sobre os problemas de saúde enfrentados pelos autores dessas ações.

Outro ponto considerado pela Recomendação foi a questão dos tratamentos experimentais, realçando-se que os medicamentos e tratamentos utilizados no Brasil dependem de prévia aprovação pela ANVISA, como forma de garantir a saúde dos usuários contra práticas com resultados ainda não comprovados ou mesmo contra aqueles que possam ser prejudiciais aos pacientes. Com base nisso, a Recomendação $n^{\circ} 31 / 2010$ orientou aos Tribunais de Justiça dos Estados (TJ) e aos Tribunais Regionais Federais (TRF) que:

a) celebrassem até dezembro de 2010 convênios com o objetivo de disponibilizar apoio técnico composto por médicos e farmacêuticos para auxiliar os magistrados na formação de um juízo de valor quanto à apreciação das questões clínicas apresentadas pelas partes das ações relativas à saúde;

b) incluam a legislação relativa ao direito sanitário como matéria individualizada no programa de direito administrativo dos respectivos concursos para ingresso na carreira da 
magistratura;

c) promovam, para fins de conhecimento prático de funcionamento, visitas dos magistrados aos Conselhos Municipais e Estaduais de Saúde, bem como às unidades de saúde pública ou conveniadas ao SUS, dispensários de medicamentos e a hospitais habilitados em Oncologia; e

d) orientem, através das suas corregedorias, os magistrados vinculados que: $i$ ) procurem instruir as ações, tanto quanto possível, com relatórios médicos, com descrição da doença, inclusive CID, contendo prescrição de medicamentos, com denominação genérica ou princípio ativo, produtos, órteses, próteses e insumos em geral, com posologia exata; ii) evitem autorizar o fornecimento de medicamentos ainda não registrados pela ANVISA, ou em fase experimental, ressalvadas as exceções expressamente previstas em lei; iii) ouçam, quando possível, preferencialmente por meio eletrônico, os gestores, antes da apreciação de medidas de urgência; $i v)$ verifiquem, junto à Comissão Nacional de Ética em Pesquisas (CONEP), se os requerentes fazem parte de programas de pesquisa experimental dos laboratórios, caso em que estes devem assumir a continuidade do tratamento; $v$ ) determinem, no momento da concessão de medida abrangida por política pública existente, a inscrição do beneficiário nos respectivos programas.

A implementação e execução da política pública judiciária da saúde, delineada na Recomendação n ${ }^{\circ} 31$, foi conferida, através da Resolução no 107/2010 - que, ao contrário da primeira, tem caráter vinculante -, ao Fórum do Judiciário para a Saúde, ou simplesmente Fórum da Saúde, que tem por escopo o monitoramento e a resolução das demandas de assistência à saúde.

O Fórum é constituído pelo Comitê Executivo Nacional e Comitês Executivos Estaduais (submetidos ao primeiro). Tais comitês têm por objetivo a coordenação e a execução de ações de natureza específica, que forem consideradas relevantes, ficando sob a coordenação de magistrados indicados pela Presidência do CNJ e/ou pela Corregedoria Nacional de Justiça.

Estes Comitês são compostos por magistrados atuantes em unidades jurisdicionais, especializadas ou não, que tratem de temas relacionados à saúde, podendo contar com o auxílio de autoridades e especialistas com atuação na área da saúde, especialmente do Conselho Nacional do Ministério Público, do Ministério Público Federal, dos Estados e do Distrito Federal, das Defensorias Públicas, da Ordem dos Advogados do Brasil, de universidades e outras instituições de pesquisa. 
O Fórum Nacional da Saúde tem como atribuições o monitoramento das ações judiciais que envolvam prestações de assistência à saúde e o Sistema Único de Saúde, além da proposição de medidas concretas e normativas voltadas à otimização de rotinas processuais, à organização e estruturação de unidades judiciárias especializadas e à prevenção de conflitos judiciais.

O Fórum objetiva, ainda, a produção de enunciados a serem utilizados pelos juízes de todo o País em decisões sobre funcionamento de medicamentos, cobertura de planos de saúde e outros temas mais frequentemente levados à Justiça. As ações do Fórum são pensadas principalmente em eventos científicos nacionais e estaduais, nos quais são traçadas as diretrizes de atuação e estabelecido debates e estudos que venham a mobilizar os diversos segmentos da área da saúde, notadamente os Membros do Judiciário, do Ministério Público, gestores e Executores de Políticas Públicas.

A partir da análise da Resolução107/2010 e das Recomendações 31/2010 e 43/2013, percebe-se que o Conselho Nacional de Justiça pretende colocar-se como um ator de uma efetiva política pública judiciária de defesa e garantia do direito à saúde, através da expedição de recomendações de condutas e enunciados para orientar os magistrados nos processos de saúde e da aproximação do Poder Judiciário com o Poder Executivo.

O Poder Judiciário, portanto, para solucionar as dificuldades advindas do fenômeno da judicialização da saúde, resolveu elaborar uma política pública judiciária, articulando diferentes sujeitos (magistrados, promotores, gestores públicos, usuários do SUS e profissionais da saúde) e procurando conciliar diversos interesses e expectativas em torno da temática.

A política judiciária objetiva oferecer alternativas para as dificuldades encontradas pelos magistrados na apreciação dos pedidos de prestações em saúde. O CNJ procurou corrigir o problema da falta de diálogo dos magistrados com o Executivo, que acaba, na maioria das vezes, por comprometer a própria efetividade (e por que não o acerto?) das decisões judicias. Percebeu-se a capacidade institucional do Poder Judiciário, que nem sempre está mais habilitado à produção da melhor decisão na área da saúde, e os efeitos sistêmicos dos comandos judiciais, desrespeito ou desorganização das políticas públicas.

A partir dessa percepção, buscou-se aproximar os agentes envolvidos na decisão (juiz, gestores e mercado - no caso da saúde suplementar) e estimular uma maior cooperação na procura de melhores respostas para as questões de saúde, tudo através da inserção, nas 
demandas individuais, da teoria do diálogo institucional que, conforme observa Souza (2013, p. 296),

[...] partindo da premissa de que o Judiciário não é a última palavra, acredita no valor epistêmico da democracia, trabalhando para promover uma interação virtuosa entre os centros decisórios responsáveis pelo comando do sistema público de saúde, no qual todos são enxergados em relação de horizontalidade e dotados de virtudes e vícios.

Em prol da inserção do diálogo institucional, a Recomendação $n^{0} 31$ orienta-os a ouvirem, quando possível, os gestores, antes da apreciação das liminares e a visitarem os Conselhos Municipais e Estaduais de Saúde, as unidades de saúde pública ou conveniadas ao SUS, os dispensários de medicamentos e hospitais habilitados em oncologia.

A política pública judiciária do CNJ busca, ainda, fornecer parâmetros decisórios para os magistrados, que são fundamentais para evitar-se a insegurança e o decisionismo no campo da judicialização da saúde, visto que a amplitude e complexidade do direito à saúde oferecem sérias dificuldades aos juízes. Além de tentar estabelecer o diálogo entre o Poder Judiciário e o Poder Executivo e de fixar parâmetros decisórios para os magistrados, a Recomendação $\mathrm{n}^{\mathrm{o}} 31$ reconheceu a necessidade de um olhar transdisciplinar do Judiciário em relação ao direito à saúde, buscando fornecer "apoio técnico composto por médicos e farmacêuticos para auxiliar os magistrados na formação de um juízo de valor quanto à apreciação das questões clínicas apresentadas pelas partes das ações relativas à saúde" (Resol. 31/2010, I) (BRASIL, 2010, p. 3).

Com efeito, a correta aplicação e interpretação do direito à saúde exige um aprofundamento nas áreas de direito constitucional, administrativo e sanitário, bem como em questões técnicas, científicas, políticas e econômicas. No entanto, a composição desses núcleos de apoio técnico aos juízes (ou seja, por médicos e farmacêuticos) revela que o CNJ trabalha com um conceito de saúde puramente medicalizado, o qual já foi superado há muito, uma vez que não consegue abarcar as pessoas que tenham problemas psicológicos e sociais, os quais são muito frequentes na sociedade do século XXI.

Assim, a instituição desses núcleos não é suficiente para fornecer o devido apoio aos magistrados na resolução das demandas envolvendo o direito à saúde, pois a saúde é um fator complexo, que envolve uma série de elementos físicos, sociais e mentais, não sendo, portanto, as políticas e questões de saúde atinentes apenas a médicos e farmacêuticos, pelo que a composição desses núcleos deveria ser ampliada. Nessa linha, Rocha e Webber (2012, p. 181) alertam que 
Essa necessidade da adoção de um olhar transdisciplinar vai além de se ter em um processo dessa natureza mero laudo elaborado pelo Departamento Médico Judiciário ou por um perito nomeado. A complexidade envolvida na questão não permite que se encontre uma solução menos gravosa e quiçá ideal para a situação apenas com um laudo pericial sem a oportunidade de manifestação dos demais subsistemas envolvidos. Em casos como o presente, é necessário que se considerem as comunicações advindas dos diversos subsistemas sociais, como o subsistema da Economia, o subsistema do Direito, o subsistema da Saúde e o subsistema da Política. É preciso que se permita a cada um deles demonstrar o seu ponto de observação sobre a questão.

Além disso, pelos moldes do CNJ, a interação dos núcleos de apoio técnico com os magistrados será somente documental, isto é, o juiz, através de um despacho, encaminhará o processo para o núcleo emitir parecer, retornando, após isso, os autos ao gabinete do magistrado. O contato será apenas através do papel, quando a complexidade das demandas exige que se estabeleça uma efetiva mesa de diálogos, que permita o contato direito dos magistrados com os profissionais especializados. É preciso também ter cuidado com a ligação estrita desses núcleos às Secretarias de Saúde, circunstância que pode afetar a legitimidade de seus pareceres. Nesse ponto, cite-se as sugestões apresentadas por Ferreira e Costa (2013, p. 227):

\begin{abstract}
Seguindo essa linha de pensamento, talvez se devesse pensar em duas sugestões: a) a criação de um quadro plural de servidores, composto não apenas por médicos e técnicos das Secretarias do Estado, mas também por um corpo técnico independente que integrasse o próprio tribunal, tal como ocorre no NAT do Tribunal de Justiça do Piauí; e b) desvinculação formal do NAT da Secretaria de Saúde dos estados e vinculação ao Tribunal de Justiça em que estiverem instalados, com o objetivo de preservar uma autonomia maior, o que afastaria a instabilidade sentida pelo defensor público geral do Mato Grosso, diante da possibilidade de ingerência dos gestores dessas secretarias.
\end{abstract}

Após a análise crítica das recomendações do CNJ, surge a indagação sobre a eficácia dos mecanismos instituídos pelo órgão após mais de cinco anos da criação da política judiciária para a objetivação e racionalização das demandas de saúde. Com vistas a obter uma possível resposta foi realizada, no ano de 2015, em Brasilia/DF, uma entrevista semiestruturada com a então Coordenadora do Comitê Executivo Nacional do Fórum do Judiciário para a Saúde.

O Comitê Executivo Nacional tem por função o exercício, em nível nacional, da coordenação do Fórum da Saúde e a execução de ações consideradas relevantes para a melhoria da prestação jurisdicional nas demandas de saúde. O Comitê, na época da pesquisa, estava sob a direção da Conselheira do CNJ Deborah Ciocci, sendo composto ainda por juízes, servidores do Poder Judiciário especialistas em direito sanitário, além de 
representantes do Ministério da Saúde, da Agência Nacional de Saúde Suplementar, da Agência Nacional de Vigilância Sanitária, do Conselho Nacional de Secretários de Saúde e do Conselho Nacional de Secretarias Municipais de Saúde.

A entrevista com a Conselheira do CNJ objetivou verificar como ocorre a condução nacional dos trabalhos do Fórum da Saúde e averiguar a eficácia de suas ações.

Apenas duas perguntas foram respondidas pela Conselheira, as demais foram respondidas por um assessor por ela designado. As perguntas realizadas diretamente à Coordenadora do Comitê Executivo Nacional foram as seguintes:

1) Qual é a percepção de Vossa Excelência sobre a judicializaçao da saúde e o Fórum Nacional do Judiciário para a saúde?

2) O Fórum foi criado há quase cinco anos durante a presidência do Min. Gilmar Mendes, cujo mandato frente ao STF e CNJ se destacou pela defesa aos direitos e garantias fundamentais. Passados 5 anos da sua criação, Vossa Excelência avalia que as ações do Fórum ainda está entre as prioridade do CNJ?

Em sua resposta, a Conselheira destacou que entende o Fórum da Saúde como "um trabalho multidisciplinar que contribui para a desjudicialização, que é a nova meta institucional do CNJ", expressa na Portaria 16/20015. Segundo ela, as ações do Fórum ainda estão entre as prioridades do Conselho Nacional de Justiça, tanto é que a referida portaria "prevê como uma das metas do órgão a garantia dos direitos fundamentais, chamando a sociedade para participar [desse processo]".

Entre os questionamentos dirigidos ao assessor da Conselheira, o primeiro a ser realizado foi o seguinte: “Qual a periodicidade das reuniões do Fórum? Existe uma agenda de tarefas a ser cumprida em 2015?”. O assessor informou que as reuniões acontecem, geralmente, uma vez por mês, mas que, em determinadas circunstâncias, há reuniões extraordinárias para a apreciação de questões específicas. Ele disse, ainda, que o Fórum "é um ambiente permanente de debate, de discussões virtuais".

$\mathrm{O}$ segundo questionamento formulado referia-se a: "Como o Fórum realiza o monitoramento das ações judiciais que envolvem prestações de assistência à saúde? Além da quantificação do número de ações, O Fórum já realizou algum estudo sobre a judicializaçao da saúde?".

Com relação à primeira parte da pergunta, o assessor disse que "com base na Resolução n ${ }^{\circ}$ 107, o Conselheiro Milton Nobre [primeiro coordenador do Fórum] pediu que criasse um sistema de acompanhamento - o Sistema da Resolução 107, que armazena os 
dados enviados pelo Tribunal sobre as ações de saúde, a partir dos quais são retirados relatórios", que permitem o monitoramento das ações judiciais envolvendo prestações de assistência à saúde.

$\mathrm{O}$ entrevistado reconheceu, todavia, que o monitoramento realizado pelo $\mathrm{CNJ}$ apresenta muitas falhas, pois verificaram que o quantitativo de demandas de saúde divulgado no site do Conselho não coincide com os números enviados por algumas Secretarias de Saúde, sendo os últimos sempre maiores. Ele explicou que é dos Tribunais brasileiros a responsabilidade de alimentar o Sistema da Resolução $\mathrm{n}^{\circ} 107$ e que o número aquém do quantitativo de ações de saúde realmente em tramitação pode ser atribuído ao fato de que os Tribunais não sabem quais dados cadastrar no Sistema, já que cada Tribunal tem um modo próprio de classificar as ações envolvendo prestação de saúde, embora exista um padrão sugerido pelo CNJ (Sistema de Gestão de Tabelas Processuais Unificadas), que, por não ser uma obrigação legal, acaba inobservado pelos Tribunais.

$\mathrm{O}$ assessor realçou, ainda, que é necessário haver um padrão melhor para o levantamento dos dados, talvez sendo o caso de realizar uma oficina nos Tribunais brasileiros de modo a possibilitar-lhes o melhor manuseio do Sistema da Resolução no 107. Além disso, frisou que "apesar de haver uma Resolução do CNJ, os Tribunais acabam não mandando os dados, porque é uma ação permanente que acaba se perdendo pela mudança de gestão".

Conforme se observa, o Conselho Nacional de Justiça, por depender dos Tribunais (que muitas vezes não estão envolvidos na política judiciária), tem tido dificuldades para quantificar as ações de saúde, o que é preocupante porque sem um cenário fidedigno do número e do tipo de ações é muito difícil oferecer soluções para os problemas gerados pela judicialização da saúde.

O Fórum não vem cumprindo de modo efetivo o que a Resolução $n^{\circ}$ 107/2010 (digase, de caráter vinculante ${ }^{3}$ ) determina que ele faça: "o monitoramento das ações judiciais que envolvam prestações de assistência à saúde, como o fornecimento de medicamentos, produtos ou insumos em geral e disponibilização de leitos hospitalares". Essa inefetividade foi constatada em por duas razões: $i$ ) porque a quantidade de demandas envolvendo o direito à saúde constante no site do Conselho não condiz com a realidade e ii) o quadro não permite

\footnotetext{
${ }^{3}$ Por força do art. $102 \S 5^{\circ}$ do Regimento Interno do CNJ, as resoluções do órgão tem força vinculante após a publicação no Diário da Justiça eletrônico e no sítio eletrônico da instituição.
} 
verificar os diversos assuntos sobre os quais as demandas versam ${ }^{4}$.

Ressalte-se que até o momento o CNJ ainda não realizou qualquer estudo sobre a judicialização da saúde e, segundo o assessor, essa não é a prioridade do órgão, "a prioridade é encontrar mecanismos para diminuir as ações". Essa afirmação demonstra claramente que a política para o aprimoramento da prestação jurisdicional em saúde é conduzida sem estar embasada em estudos sobre o panorama da judicialização no Brasil, o que causa perplexidade porque é muito difícil oferecer soluções efetivas se não se conhece o perfil e a quantidade dessas ações, as dificuldades específicas de cada Estado brasileiro no enfrentamento do tema, dentre outros fatores.

O terceiro questionamento apresentado foi o seguinte: "Como é a infraestrutura e recursos humanos disponíveis para o Fórum? Há um espaço de funcionamento próprio e servidores exclusivamente designados para a realização dos estudos sobre a judicializacao?”.

O entrevistado disse que a infraestrutura utilizada pelo Fórum é a estrutura de gabinete da coordenadora do Fórum, citando que ele, por exemplo, é a um só tempo assessor de processos da Conselheira Deborah Ciocci e do Fórum da Saúde por ela coordenado. Pontuou, ainda, que "recentemente (há um mês) foi criado no CNJ um Núcleo de Apoio às Comissões, mas que tem apenas três servidores que ainda estão em fase de levantamento de quais comissões e projetos existem. A ideia é que possam auxiliar todos os projetos e comissões".

O CNJ, ao longo de sua existência, vem lançando uma série de projetos não só na área de gestão administrativa do Judiciário, mas também de garantia aos direitos humanos fundamentais $^{5}$, sem, todavia, contar com a infraestrutura adequada para a execução e acompanhamento desses projetos.

Questionado sobre as medidas concretas e normativas voltadas à otimização das rotinas processuais e prevenção de conflitos judiciais em saúde adotadas pelo Fórum, o assessor pontuou que entre as principais medidas a edição dos seguintes atos normativos: Resolução $n^{\circ}$ 107/2010, Recomendação $n^{\circ}$ 31/2010, Recomendação $n^{\circ} \quad 36 / 2011$ e Recomendação n 43/2013.

\footnotetext{
${ }^{4}$ CONSELHO NACIONAL DE JUSTIÇA. 2010. Quantidade de demandas de saúde nos Tribunais

${ }^{5}$ Projetos que pretendem trabalhar uma infinidade de questões: conflitos de terras e trabalho escravo, assuntos fundiários, trabalho escravo, adoção de crianças e adolescentes, reconhecimento de paternidade, ressocialização dos presos e egressos do sistema carcerário, métodos consensuais de resolução de conflitos, doação de órgãos, células e tecidos, judicialização da saúde, exploração sexual, trabalhos forçados e retirada de órgãos e violência doméstica contra a mulher.
} 
Nesse contexto, observa-se que a atuação do Fórum da Saúde até o momento não ultrapassou o plano normativo, o que se considera insuficiente, na medida em que o plano dos fatos não se modifica apenas a partir de normas, sobretudo, quando editadas sem força vinculante (as recomendações têm apenas caráter de orientações dirigidas aos Tribunais e magistrados).

A Resolução nº 107/2010 atribuiu ao Fórum a tarefa de proposição, além de medidas normativas, de medidas concretas voltadas à otimização de rotinas processuais, à organização de rotinas processuais, à organização e estruturação de unidades judiciárias especializada, à prevenção de conflitos judiciais e à definição de estratégias nas questões de direito à saúde. No entanto, após cinco anos de existência do Fórum da Saúde ainda não há nenhum grande projeto objetivando o alcance de tais fins. Verificou-se que, em verdade, o Fórum atribuiu a responsabilidade da criação dessas medidas concretas para os Tribunais e a efetiva criação delas dependerá do grau de comprometimento destes órgãos com a questão da judicialização da saúde.

Sobre o acompanhamento das medidas adotadas pelos Tribunais brasileiros, o assessor informou que "foi criado pelo CNJ um processo eletrônico de acompanhamento de cumprimento de decisões, de consulta pública (Processo 0003398/62.2012.2.0000). Nesse processo, há o acompanhamento da Recomendação $n^{\circ}$ 31. Sempre pedem informações, de 6 em 6 meses, sobre a estrutura que o Tribunal está disponibilizando ao Comitê Executivo Estadual”.

Em consulta ao processo eletrônico referido, verificou-se que o $\mathrm{CNJ}$ através dele divulga os eventos promovidos pelo Fórum, bem como solicita informações dos Tribunais sobre as providências já adotadas para o cumprimento da Recomendação, todavia, não foi possível observar as informações repassadas pelos Tribunais.

Entende-se que esse acompanhamento por meio do processo eletrônico, que não é atualizado desde 29/3/2014 (BRASIL, 2015), é insuficiente, fazendo-se necessário um contato mais direto do $\mathrm{CNJ}$ com os Tribunais a fim de se certificar sobre a realidade das informações repassadas para e das dificuldades enfrentadas no cumprimento dos atos normativos do órgão.

O assessor informou que a divulgação das ações do Fórum é realizada através da "página do Fórum dentro do CNJ, sendo o site um mural de divulgação das ações estaduais", avaliando que "os juízes mais empenhados conhecem e os que têm demanda de processos muito grande não procuram saber. Poderia, todavia, haver um empenho de divulgação maior, 
todavia, a carga-horária de trabalho não permite".

Conforme se observa, o próprio Conselho reconhece que a estratégia de divulgação das ações do Fórum é insuficiente, não conseguindo atingir os magistrados. O assessor afirmou que "por mais que tentem fazer divulgação não conseguem atingir os juízes. Pedem apoio do Tribunal, mas vê que a grande maioria [dos magistrados] não conhece. Os juízes têm uma demanda muito grande e não tem condições de se aprofundarem na área. O CNJ é um órgão pequeno, dependente dos Tribunais. Uma coisa positiva são as jornadas. A primeira foi enaltecida em razão da atenção dada à judicialização. Grande parte dos juízes, todavia, não conhecem os enunciados da I Jornada, sendo inclusive um dos objetivos do CNJ fazer um levantamento sobre o impacto dos enunciados da I Jornada na jurisprudência brasileira".

Nesse contexto, tem-se que é preciso investir mais na divulgação das ações do Fórum da Saúde, até como forma de ampliar os participantes nos debates que acontecem nos encontros que vem sendo promovidos pelo CNJ para a discussão de temas relacionados à judicialização da saúde.

Sobre os núcleos de apoio técnico, o assessor disponibilizou entrevista concedida pela Conselheira Deborah Ciocci, na qual ela afirma que "os Estados de São Paulo, Minas Gerais, Rio de Janeiro, Paraná, Acre, Pernambuco, Rondônia, Piauí, Tocantins, Mato Grosso do Sul, Rio Grande do Sul, Amapá e Mato Grosso criaram Núcleos de Apoio Técnicos vinculados aos Tribunais". Portanto, apenas metade dos Estados instituíram os núcleos, sendo necessária que o CNJ intensifique o diálogo com os entes que ainda não os criaram para que verifique quais as dificuldades que estão enfrentando, uma vez que, embora os Tribunais não sejam obrigados a instalar os NAT's, essa é uma importante medida de subsídio aos juízes nas demandas de saúde.

A partir das duas entrevistas realizadas em âmbito nacional conclui-se que as ações do Fórum da Saúde têm tido pouca efetividade longo dos anos, pois, apesar de promover anualmente encontros, as suas recomendações e enunciados têm pouca penetração na jurisprudência brasileira e ainda não se conseguiu lançar em nível nacional qualquer medida concreta para o aprimoramento da prestação jurisdicional nas demandas de saúde ou para a prevenção de novos conflitos.

\section{CONSIDERAÇÕES FINAIS}


O Conselho Nacional de Justiça dirige quase exclusivamente a responsabilidade pela condução de sua política judiciária para a saúde aos Tribunais, sem haver em contrapartida um efetivo acompanhamento e auxílio do CNJ por parte dos Tribunais e juízos, uma vez que não conta com a infraestrutura adequada para a execução e acompanhamento desses projetos.

No caso específico do Fórum da Saúde, isso resultou na pouca eficácia ao longo dos anos, pois, apesar de promover anualmente encontros, as suas recomendações e enunciados têm pouca penetração na jurisprudência brasileira e ainda não se conseguiu lançar em âmbito nacional qualquer medida concreta voltada ao aprimoramento da prestação jurisdicional nas demandas de saúde ou para a prevenção de novos conflitos, à otimização das rotinas e à organização de rotinas processuais, à organização e estruturação de unidades judiciárias especializadas, à prevenção de conflitos judiciais e à definição de estratégias nas questões de direito à saúde.

Verificou-se que o CNJ tem enfrentado dificuldades para o desenvolvimento de sua política pública judiciária em prol do aprimoramento da prestação jurisdicional nas demandas de saúde. Ao Conselho, constitucionalmente, foi atribuída à gestão administrativa e disciplinar do Poder Judiciário, atribuições que por si só já consomem muito tempo da instituição, restando pouco para a condução dos programas em defesa dos direitos e garantias fundamentais que lançam.

O Poder Judiciário tem vários problemas e certamente o Conselho Nacional de Justiça não conseguirá resolver todos eles. Por isso, é preciso que seja reformulado o modo como esses programas são desenvolvidos, devendo a infinidade de projetos ser reduzidos através do estabelecimento metas claras e de prioridades quanto aos problemas que CNJ irá abordar.

Fixadas as prioridades, deve-se fornecer a estrutura adequada no interior do órgão para a condução dos programas, através da designação de servidores específicos para cada um destes projetos, que realizem estudos e acompanhem diretamente como a política está sendo conduzida no âmbito dos Estados. Caso contrário, ter-se-á sempre uma infinidade de projetos com poucos efeitos práticos, como é o caso do Fórum da Saúde, cuja Coordenadoria não conseguiu demonstrar nenhum reflexo concreto das ações desenvolvidas até agora sobre o fenômeno da judicialização da saúde.

Considera-se que, apesar das críticas realizadas ao longo do trabalho, um dos principais acertos da política pública judiciária conduzida pelo Conselho Nacional de Justiça 
na seara da judicialização da saúde é a tentativa de aproximar os magistrados dos centros de decisão do Poder Executivo, uma vez que o Poder Judiciário não é (e nem deve ser) o protagonista no campo das políticas públicas de saúde. O melhor caminho para o fortalecimento do Sistema Único de Saúde e, por conseguinte, para a efetivação do direito à saúde é a racionalização do processo de interação entre os agentes do sistema jurídico e administrativo através do estabelecimento de um diálogo institucional.

As decisões judiciais não devem ser o ponto de chegada, mas sim o ponto de partida de um processo de mudança social mais amplo e complexo, devendo o diálogo institucional ser estimulado não só como uma forma de melhorar as decisões judiciais, mas também de ensejar efetivas mudanças na sociedade a partir da transferência para o Executivo e Legislativo de um problema que teve destaque no Poder Judiciário.

E para que o Poder Judiciário atue como um identificador de problemas sociais é salutar que se demonstre aos Tribunais a importância de se montar um banco de dados efetivo sobre as ações de saúde, que informe não apenas o dado quantitativo, mas também o perfil dos demandantes e a natureza das prestações requerida, informações que devem ser de fácil acesso a toda a população, a exceção dos processos que tramitam em segredo de justiça, por determinação constitucional, no que se refere à publicidade. Ademais, faz-se necessário que haja uma interlocução periódica entre o Executivo e o Poder Judiciário acerca das ações ajuizadas no sistema de justiça brasileiro.

E, por fim, tem-se que o Poder Judiciário precisa ter em mente que se é certa a necessidade do desenvolvimento de ações para a resolução de aspectos problemáticos da juridicilização da saúde, também é preciso que se invista em caminhos alternativos ao fenômeno através do estímulo à instrumentos de desjudicialização das demandas de saúde.

\section{REFERÊNCIAS}

BRASIL. Conselho Nacional de Justiça. Relatório atualizado da Resolução 107. 2011. Disponível em:

<http://www.cnj.jus.br/images/programas/forumdasaude/relatorio_atualizado_da_resolucao10 7.pdf>. Acesso em 18 fev. 2014.

. Relatórios de cumprimento da Resolução CNJ n. 107. 2014. Disponível em: <http://www.cnj.jus.br/images/programas/forumdasaude/demandasnostribunais.forumSaude.p df $>$. Acesso em 18 fev. 2014.

. Resolução no 31, de 30 de março de 2010. Disponível em: 
<http://www.cnj.jus.br/images/atos_normativos/recomendacao/recomendacao_31_30032010_ 22102012173049.pdf>. Acesso em 19 maio 2015.

Resolução no 107, de 6 de abril de 2010. Disponível em:

<http://www.cnj.jus.br/images/atos_normativos/resolucao/resolucao_107_06042010_111020 12191858.pdf>. Acesso em: 19 maio 2015.

. Sistema de processo eletrônico. 2015. Disponível

em:〈https://www.cnj.jus.br/ecnj/index.php>. Acesso em: 20 mar. 2015.

BRASIL. Tribunal de Contas da União. Relatório Sistêmico de Fiscalização da Função

Saúde. 2015.Disponível em:

<https://contas.tcu.gov.br/juris/SvlHighLight?key=41434f5244414f2d434f4d504c45544f2d31 363039373236\&sort=RELEVANCIA\&ordem=DESC\&bases=ACORDAO-

COMPLETO; \&highlight $=\&$ posicaoDocumento $=0 \&$ numDocumento $=1 \&$ totalDocumentos $=1>$ . Acesso em 25 set. 2016.

BRITO FILHO, José Cláudio Monteiro de. Direito fundamental à saúde: propondo uma concepção que reconheça o individuo como seu destinatário. Revista de Direito

Internacional dos Direitos Humanos, Rio Grande do Norte, v. 2, n. 1, p. 168-182, jan./jun. 2014.

DELDUQUE, Maria Célia; MARQUES, Silvia Badim; CIARLINI, Álvaro. Judicialização das políticas de saúde no Brasil. In: ALVES, Sandra Mara Campos; DELDUQUE, Maria Célia; DINO NETO, Nicolao (Org.). Direito sanitário em perspectiva. Brasília: ESMPU: FIOCRUZ, 2013. p. 181-217.

FERREIRA, Siddharta Legale; COSTA, Aline Matias da. Núcleos de assessoria técnica e judicialização da saúde: constitucionais ou insconstitucionais?. Revista da Seção Judiciária do Rio de Janeiro, Rio de Janeiro, v. 20, n.36, p. 219-240, abr. 2013.

FREGALE FILHO, Roberto. Conselho Nacional de Justiça: desenho institucional, construção de agenda e processo decisório. Dados - Revista de Ciências Sociais, Rio de Janeiro, v. 56, n. 4, p. $975-1007,2013$.

GOMES, Dalila F. et al. Judicialização da saúde e a audiência pública convocada pelo Supremo Tribunal Federal em 2009: o que mudou de lá pra cá?, Saúde debate, Rio de Janeiro, vol.38, n.100, p. 139-156, jan./mar. 2014.

MENDES, Gilmar. As contribuições do CNJ para o Judiciário brasileiro. 2012. Disponível em: <http://www.editorajc.com.br/2012/07/as-contribuicoes-do-cnj-para-ojudiciario-brasileiro/>. Acesso em: 6 fev. 2015.

PERLINGEIRO, Ricardo. A tutela judicial do direito público à saúde no Brasil. Revista Direito, Estado e Sociedade, Rio de Janeiro, n.41, p. 184-203, jul./dez. 2012.

RAMOS, Edith Maria Barbosa. Universalidade do direito à saúde. São Luís: EDUFMA, 2014. 
ROCHA, Leonel Severo; WEBBER, Suelen. A efetivação do direito à saúde sob uma observação transdisciplinar, Direitos Culturais, Santo Ângelo, v. 7, n. 12, p. 167-186, jan./jun. 2012.

SADEK, Maria Tereza Aina. Poder Judiciário: uma nova instituição. In: DANTAS, Humberto et. al. (Org.). Reforma do Estado brasileiro: perspectivas e desafios. Rio de Janeiro, Fundação Konrad Adenauer, 2010.

SOUZA, Jorge Munhós de. Diálogo institucional e direito à saúde. Salvador: JusPODIVM, 2013.

WERNER, Patrícia Ulson Pizarro. O Direito Social e o Direito Público Subjetivo à Saúde: o desafio de compreender um Direito com duas faces, Revista de Direito Sanitário, São Paulo, v. 9, n. 2, p. 92-131, 2008. 